Editorial

\title{
Terapias celulares en Oncología
}

Los tratamientos actuales del cáncer se basan principalmente en una combinación de cirugía, radioterapia y quimioterapia, esta última a través de una administración sistémica de los fármacos. A menudo es difícil obtener una alta concentración intratumoral de las drogas, debido a la aparición de efectos secundarios inaceptables. En los últimos años se han realizado avances significativos en el desarrollo de nuevas terapias dirigidas específicamente al tumor, como son el uso de anticuerpos o de vectores virales. Sin embargo, no poseen una señal específica que les guíe hacia el tumor y presentan problemas específicos como es su tiempo de vida media en la circulación sanguínea, la adherencia no específica a otros tejidos, dificultades para extravasarse o la activación del sistema inmune contra el fármaco. En este contexto, un fármaco ideal sería un vehículo terapéutico con capacidad para dirigirse específicamente al tumor, extravasarse y sin presentar problemas de inmunidad. Una opción especialmente atractiva para ejercer de vehículo terapéutico es el uso de células que sean atraídas por el propio tumor.

Algunos tipos celulares (linfocitos, progenitores endoteliales, macrófagos...) parecen ser reclutados por el tumor durante su desarrollo. Así, por ejemplo, los tumores, durante su etapa proliferativa, inducen al tejido circundante a la formación de nuevos vasos sanguíneos al secretar factores de crecimiento como el VEGF o el FGF. Otros factores secretados por las células tumorales, como el SDF-1, inducen la migración de ciertas células inmunes. En contraste con las drogas de uso habitual en la clínica, las células no se distribuyen aleatoriamente a través de la circulación, sino que poseen su propio programa de distribución por el organismo. Si armásemos a estas células con ciertos agentes antitumorales sería posible desarrollar una nueva estrategia terapéutica, idealmente más específica, al ejercer una acción local y exclusiva sobre el tumor. Esta revisión resumirá brevemente los progresos que se han realizado recientemente utilizando células como portadoras de productos terapéuticos.

\section{Tipos de vehículos celulares}

Las células del sistema inmune como los linfocitos, los macrófagos, las células NK y los eosinófilos, o las células relacionados con neoangiogénesis tumoral, son las opciones más obvias para ser utilizadas como vehículos celulares, pero otros tipos de células también se podrían utilizar, cómo por ejemplo las propias células tumorales o las células madre adultas. Hoy en día no hay un vehículo celular perfecto pero se están realizando aproximaciones prometedoras.

\section{A) Células del sistema inmune}

La mayoría de los trabajos en marcha utilizando células del sistema inmune buscan solamente su activación. Dicha activación es un proceso muy complejo del que no poseemos en la actualidad todas las claves para realizar con éxito este tipo de terapias. Sin embargo los protocolos de inmunoterapia nos pueden indicar, indirectamente, la capacidad de las células del sistema inmune para ser utilizadas como vehículos celulares de agentes antitumorales. Así se han utilizado leucocitos de sangre periférica, cultivados in vitro en presencia de diversas citoquinas, en especial IL-2, para obtener linfocitos activados. Se han realizado ensayos clínicos combinando la administración de IL-2 y de linfocitos activados y los efectos antitumorales se han correlacionado con la dosis de IL-2 y el número de células administradas. Por otro lado, los linfocitos que infiltran los tumo- 
res poseen una actividad única antitumoral y pueden ser expandidos ex vivo también con IL-2. Estas células se han utilizado ya en terapias inmunomoduladoras, especialmente con melanomas, obteniéndose respuestas parciales clínicas en los pacientes tratados con la infusión de estos linfocitos. También se ha pensado en utilizar células NK, con la ventaja de que pueden ser obtenidas fácilmente de la sangre periférica de los pacientes. Sin embargo, y en contraste con los linfocitos, con las células NK no se ha encontrado evidencia de beneficios en ensayos clínicos, a pesar incluso de haberse demostrado su acumulación dentro de las metástasis de los pacientes. Algo similar se obtuvo utilizando macrófagos, los cuales eran eficaces a la hora de localizar las metástasis y acumularse alrededor de éstas pero los tumores primarios no regresaron. En la actualidad todos estos protocolos clínicos se basan en la capacidad natural de las células del sistema inmune para ejercer su respuesta inmune. Para inducir una citotoxicidad más alta se esta investigando principalmente en dos estrategias. Una, mejorar la presentación antigénica y/o aumentar la afinidad de este complejo con el TCR. Otra segunda estrategia se focaliza en la mejora de la activación a través de señales coestimulatorias, basada en moléculas como las de las familias B7 y TNF.

\section{B) Células tumorales}

El uso de células tumorales como vehículos terapéuticos podría parecer extraño a priori, pero existen datos que indican que puede ser efectiva. Dos grupos de investigación publicaron, en sus modelos animales respectivos, que la infusión de células del tumor hacía que éstas se localizasen preferentemente en las áreas tumorales. Además, cuando cargaron estas células malignas con vectores terapéuticos obtuvieron una reducción significativa del tamaño del tumor. Sin embargo, sus modelos se basaban en tumores implantados en áreas muy localizadas, como el cerebro y la cavidad peritoneal. En esta línea de trabajo nuestro grupo ha desarrollado un modelo murino de metástasis espontánea, donde demostramos que células tumorales inyectadas intravenosamente (i.v.) anidaban en torno a las metástasis preexistentes ${ }^{1}$. La idea de utilizar de esta manera las propias células tumorales como vehículos terapéuticos se basa en el conocimiento de que, en general, las metástasis se presentan en órganos determinados según el tipo de tumor. Esta localización preferencial se debe al hecho de que las células tumorales que viajan en la circulación sanguínea responden a los factores producidos en los diversos órganos, a las señales del endotelio y a su capacidad de anidar en sitios específicos. Nuestra hipótesis es que las células tumorales que infundimos i.v. responderán de la misma forma a las señales comentadas, con lo que se alojarán preferentemente en los mismos sitios. En un modelo preclínico demostramos que las células tumorales inyectadas i.v. se localizaron en las lesiones metastásicas preexistentes y que, además, transduciendo estas células con vectores terapéuticos (con genes suicidas o virus oncolíticos), obtuvimos una remisión significativa de las lesiones tumorales.

\section{C) Células madre adultas}

Hasta hace poco tiempo se pensaba que las células madre adultas específicas de un órgano se hallaban restringidas a ese linaje celular, pero trabajos recientes han demostrado que estas células madre pueden diferenciarse hacia multitud de tejidos y tipos celulares. Además, varios grupos han publicado que algunas células madre podrían localizarse en los tumores, en especial las células madre endoteliales, ya que el tumor al crecer necesita vascularización, promoviendo el reclutamiento de células progenitoras endoteliales. Este hecho puede ser utilizado para introducir agentes terapéuticos en el tumor utilizando estos progenitores como vehículos celulares.

Otro tipo de célula madre adulta que se puede alojar en los tumores son las células madre mesenquimales (MSC). Se ha publicado la detección de MSC en el interior de los tumores después de que estas células fueran administradas i.v. en ratones con melanoma. Por otra parte, se obtuvo una prolongación de la supervivencia cuando se indujo la secreción de IFN-gamma por las MSC. Otra estrategia se basa en el uso de las células ma- 
dre nerviosas (NSC), con las que se ha demostrado que dichas NSC pueden anidar en los tumores primarios del cerebro. Este estudio también demostró la reducción de tumores establecidos cuando se usaron NSC transducidas con genes suicidas. Además, se ha utilizado las NSC con virus oncolíticos y se obtuvo una distribución del vector a lo largo de las células del glioma.

\section{Conclusiones}

El uso de células como terapias antitumorales es una aproximación terapéutica muy novedosa. Sin embargo necesitamos mejorar nuestro conocimiento de los mecanismos por los que estas células se alojan específicamente en el tumor. Por otra parte, los investigadores preclínicos necesitan determinar las características de estas células y las técnicas de manipulación. Finalmente, los clínicos necesitarán adaptar regímenes terapéuticos para producir un resultado clínico relevante con esta nueva tecnología. En conclusión, estas células, usadas a modo de Caballo de Troya, pueden ser una alternativa terapéutica para ciertos tumores refractarios dentro de pocos años.

J. García Castro, M. Ramírez Orellana, A. Pérez Martínez, L. Madero López Servicio de Oncología y Trasplante Hematopoyético Hospital Infantil Universitario Niño Jesús Madrid (España)

\section{Referencias}

1. García-Castro J, Martínez-Palacio J, Lillo R, García-Sánchez F, Alemany R, Madero L, Bueren JA, Ramírez M. Tumor cells as cellular vehicles to deliver gene therapies to metastatic tumors. Cancer Gene Ther 2005; 12(4):341-349. 